\title{
Reply to comments on "Efficacy of modified FOLFOX6 chemotherapy for patients with unresectable pseudomyxoma peritonei"
}

\author{
Sakura Hiraide ${ }^{1,2} \cdot$ Keigo Komine $^{2,3} \cdot$ Masanobu Takahashi $^{2,3} \cdot$ Chikashi Ishioka $^{1,2,3}$ (D)
}

Received: 30 November 2020 / Accepted: 12 January 2021 / Published online: 6 February 2021

(c) The Author(s) 2021

We thank Dr. Luo and Dr. Li for providing comments regarding our manuscript entitled "Efficacy of modified FOLFOX6 chemotherapy for patients with unresectable pseudomyxoma peritonei".

They proposed that our study was a retrospective cohort study rather than a retrospective case series, and cited the description proposed by Dr. Dekker et al. [1]. From their distinguishing method between cohort studies and case series [1], our study meets the characteristic of cohort study: the patients were sampled on the basis of exposure, not a specific outcome, and followed over time to assess the occurrence of the outcomes. This description would be a nice candidate method to distinguish between cohort studies and case series, however, we do not think that this description has been completely regarded as a world-wide consensus.

For example, some researchers proposed that cohort studies differ from case series in that a comparison group is used for analysis of the treatment outcomes [2, 3]. In addition, the Strengthening the Reporting of Observational Studies in the Epidemiology (STROBE) recommendations refer to three main study designs including cohort, case-control, and cross-sectional studies, but do not specifically address case reports and case series [4]. The definition of case series has thus remained to be fully determined.

Taken together, at present, we consider that our study is not out of a case series. We completely agree with Dr. Luo and Dr. Li that the distinction between cohort studies and case series needs to be clarified in the future.

Chikashi Ishioka

chikashi@tohoku.ac.jp

1 Department of Clinical Oncology, Tohoku University Graduate School of Medicine, 2-1, Seiryo-machi, Aoba-ku, Sendai 980-8575, Miyagi, Japan

2 Department of Clinical Oncology, Institute of Development, Aging and Cancer, Tohoku University, Aoba-ku, Sendai, Miyagi, Japan

3 Department of Medical Oncology, Tohoku University Hospital, Aoba-ku, Sendai, Miyagi, Japan

\section{Compliance with ethical standards}

Conflict of interest Chikashi Ishioka received research funding from the Tokyo Cooperative Oncology Group. Chikashi Ishioka received contributions from Chugai Pharmaceutical, Asahi Kasei Pharma Corporation, Ono pharmaceutical, MSD, Pfizer, AstraZeneca, BristolMyers Squibb, Janssen Pharmaceutical, Taiho Pharmaceutical, Eisai Pharmaceutical, Daiichi Sankyo Company, Limited, and Takeda Pharmaceutical. Masanobu Takahashi has received research funding from Ono Pharmaceutical Company. Chikashi Ishioka is a representative of Tohoku Clinical Oncology Research and Education Society, a specified non-profit corporation.

Open Access This article is licensed under a Creative Commons Attribution 4.0 International License, which permits use, sharing, adaptation, distribution and reproduction in any medium or format, as long as you give appropriate credit to the original author(s) and the source, provide a link to the Creative Commons licence, and indicate if changes were made. The images or other third party material in this article are included in the article's Creative Commons licence, unless indicated otherwise in a credit line to the material. If material is not included in the article's Creative Commons licence and your intended use is not permitted by statutory regulation or exceeds the permitted use, you will need to obtain permission directly from the copyright holder. To view a copy of this licence, visit http://creativecommons.org/licenses/by/4.0/.

\section{References}

1. Dekkers OM, Egger M, Altman DG et al (2012) Distinguishing case series from cohort studies. Ann Intern Med 156:37-40

2. Bryant DM, Willits K, Hanson BP (2009) Principles of designing a cohort study in orthopaedics. J Bone Joint Surg Am 91(Suppl 3):10-14

3. Kooistra B, Dijkman B, Einhorn TA et al (2009) How to design a good case series. J Bone Joint Surg Am 91(Suppl 3):21-26

4. Vandenbroucke JP, von Elm E, Altman DG et al (2007) Strengthening the Reporting of Observational Studies in Epidemiology (STROBE): explanation and elaboration. Ann Intern Med 147:W163-W194

Publisher's Note Springer Nature remains neutral with regard to jurisdictional claims in published maps and institutional affiliations. 